\title{
Experimental Investigation on Diesel Engines by Swirl Induction with Different Manifolds
}

\author{
P. Ramakrishna Reddy ${ }^{\dot{A}^{*}}$, K. Govinda Rajulu ${ }^{\dot{B}}$ and T. Venkata Sheshaiah Naidu ${ }^{\dot{C}}$ \\ ${ }^{\dot{A}}$ Royal Institute of Technology \&Science, Department of Mechanical Engineering ,Hyderabad(AP),India \\ ${ }_{\mathrm{B}}^{\mathrm{B}}$ JNTUCEA, Department of Mechanical Engineering, JNTUA Anantapur (AP),India \\ ${ }^{\mathrm{C}}$ Vardhaman College of Engineering, Shamshabad, Hyderabad, AP
}

Accepted 10 January 2014, Available online 01 February 2014, Special Issue-2, (February 2014)

\begin{abstract}
The aim of paper is to design different types of inlet manifolds for the Internal Combustion Engine in order to create the turbulence by swirl. A good swirl promotes the fast combustion and improves the efficiency. The engine should run at low speeds in order to have low mechanical losses and fast combustion, enabling good combustion efficiency. Therefore to produce high turbulence prior to combustion within the cylinder, swirl induced by the inlet channel within the cylinder head will be helpful. In view this, experimental investigation has been carried out to find the effect of swirl on the performance of the engine as well as on its emissions, by inducing swirl with different inlet manifolds having helical, spiral and helical-spiral shapes. Detailed analysis has been carried out and discussion on the experimental results is presented in this paper work. At the outset, it is inferred that, the helical-spiral inlet manifold gives better performance and yields less emissions compared to spiral, helical and normal inlet manifolds.
\end{abstract}

Keywords: Swirl induction, Numerical simulation, Spiral manifold, Helical manifold, Helical-spiral manifold, Internal combustion, Diesel engine, fluid dynamics.

\section{Introduction}

\subsection{Swirl Induction}

${ }^{1}$ Swirl is one of the principal means to ensure rapid mixing between fuel and air in Diesel Injection diesel engine, and is used in gasoline engines to promote rapid combustion. The swirl level at the end of the compression process dependent upon the swirl generated during intake process and how much it is amplified during the compression process. In Diesel Injection diesel engine, as fuel is injected, the swirl converts it away from the fuel injector making fresh air available for the fuel about to be injected.

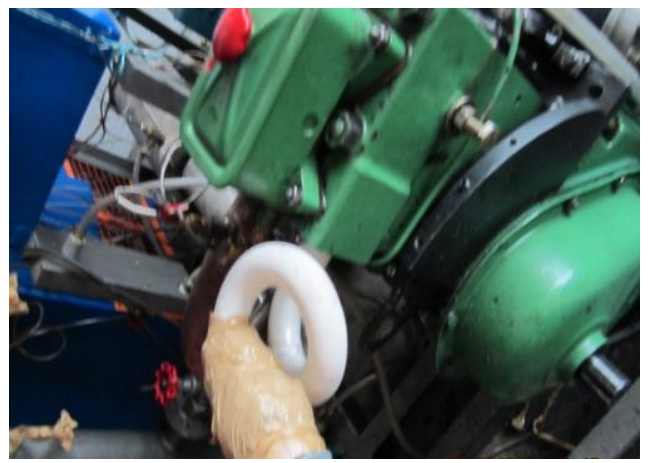

Fig.1 Helical inlet manifold with Experimental Engine

*Correspinding author: P. Ramakrishna Reddy

DOI: http://dx.doi.org/10.14741/ijcet/spl.2.2014.91
The induction swirl is generated either by tangentially directing the flow into the cylinder using directed ports or by pre swirling the incoming flow by use of a helical or spiral or helical-spiral ports. Helical ports are more compacted than normal manifold. They are capable of producing more swirl than directed ports at low lifts, but are inferior at higher lifts. Either design creates swirl at the expense of volumetric efficiency. In trying to optimize the port design for both good swirl and volumetric efficiency, current high swirl ports are in part of both directed and different technique inlet manifolds. Experimental engine setup with helical inlet manifold as shown in figure.

Control of flow through the manifold is critical for meeting the emission regulations and fuel economy requirements.

Parameters like engine speed, manifold and combustion chamber configuration (Chen et al., 1998) directly influence the swirl in DI diesel engines and subsequently it plays a vital role in mixing air and fuel inside the cylinder. Optimization of swirl becomes an important aspect in the design of intake systems of diesel engines.

Nowadays, with the availability of powerful computers, the CFD prediction methods for in-cylinder flow of IC engines have become popular. They can give very useful information regarding the flow pattern and has the potential to reduce the total development time of the intake system of an IC engine. Engine manufactures require precise engine design to bring the end product to 
the market in a short time period and hence CFD codes play an important role in IC engine design.

Bugrake (1981) presented a flow model to predict the swirl vortices and turbulence in an open chamber cup-inpiston engine. The work was compared with experimental data over a range of engine intake manifold and combustion chamber configurations. Lot of work has been done on engine flow and on the parameters that affect the turbulence, performance and emissions in a DI diesel engine. Kim et al. (1999) carried out the modeling of flow distribution in exhaust manifold. Modifications were made on the inlet and exhaust manifolds based on the results obtained. They also conducted experiments and validated the performance and emissions of the engine. Akira et al. (1990) presented an experimental analysis for turbulence inside the combustion chamber of direct injection diesel engine. From This study I understand the effects of piston bowl shape, engine speed, manifold shape and compression ratio on the flow fields in a DI diesel engine. Chiavola et al. (2001) conducted a study on the flow behavior in intake and exhaust system of an internal combustion engine and observed that the flow phenomenon in ducts closely affects the volumetric efficiency of the engine.

From the review of literature, I can analyze the design of inlet manifold configuration is very important in an IC engine. Hence, this information looks up on the effect of helical, spiral, and helical-spiral combined configuration on the induced mean swirl velocity in the piston bowl at TDC, swirl ratio during suction and compression stroke, turbulent kinetic energy variation and volumetric efficiency at engine speed $3000 \mathrm{rpm}$.

Objective of the study is

- Modeling the engine with inlet valve, exhaust valve and manifold

- Effect of inlet manifold configurations on the in-cylinder flow

- Turbulence in a diesel engine under non-firing conditions - Effect of different (helical, spiral, helical-spiral) inlet manifold configurations on volumetric efficiency, turbulence, and swirl in the engine.

\section{Experimental Set Up}

The experimental set up consists of engine, an alternator, electrical load system, fuel tank along with immersion heater, exhaust gas measuring digital device and simple $\mathrm{U}$ tube manometer.

\section{Engine}

The engine supplied by Kiloskar AV-1 Company with single cylinder vertical type four stroke, Water cooled, compression ignition engine having self governing (specifications are given in Appendix 1) is used in the present work.

\subsection{Various Parts of Experimental Setup}

Make of the engine $\quad$ : KIRLOSKAR AV-1
General details

(water cooled),

Compression ignition

Number of cylinders : One

Bore $\quad: 80 \mathrm{~mm}$

Stroke $\quad: 110 \mathrm{~mm}$

Rated output $\quad: 3.7 \mathrm{~kW} / 1500 \mathrm{rpm}$

Compression ratio $\quad: 16.5: 1$

Cylinder capacity $\quad: 553 \mathrm{cc}$

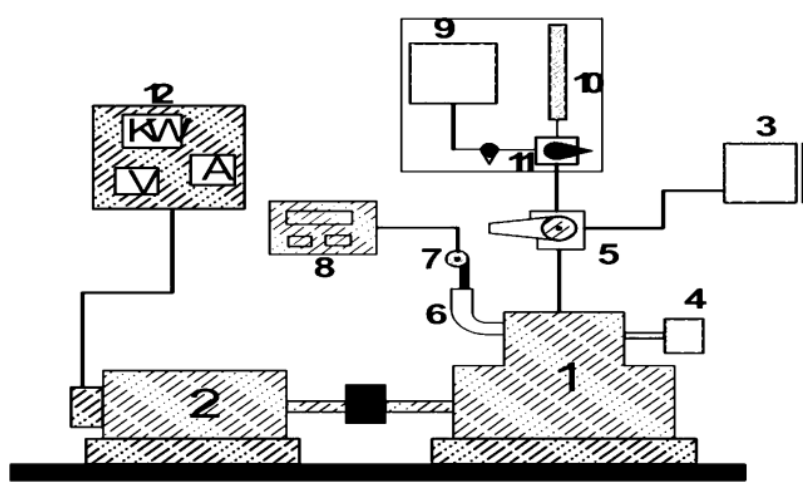

Fig. 2 Experimental Setup of the Test Engine

Prototypes may also require minor cleaning and surface treatment. Sanding, sealing, and/or painting the model will improve its appearance and durability. After removing support structures the manifolds is shown in figures below
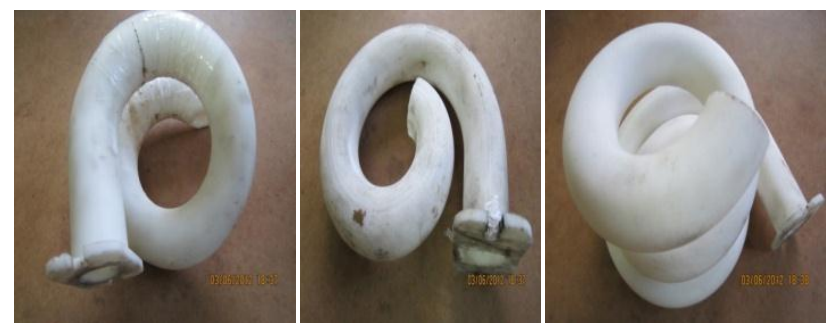

Fig.3 Helical, Spiral and Helical Spiral manifold

\section{Results and Discussion}

\subsection{Engine Performance}

\subsubsection{Brake Specific Fuel Consumption (bsfc)}

The bsfc is a measure of engine efficiency. In fact, bsfc and engine efficiency are inversely related, so that the lower the bsfc the better the engine. Engineers use the bsfc rather than thermal efficiency because a more are less universally accepted definition of thermal efficiency does not exist. The variation of brake specific fuel consumption at different load for normal, spiral, helical and helicalspiral inlet manifolds is shown in figure. 4 Brake specific fuel consumption of different inlet manifolds are vary similar to normal manifold. bsfc increases with load up to $0.5 \mathrm{~kW}$,however as load further increases from 0.5 to 3 $\mathrm{kW}$. It can be observed from the Figure. 4 that brake specific fuel consumption for all new technique manifolds is less compared to normal manifold. The values of brake specific fuel consumption of normal, spiral, helical, 
helical-spiral inlet manifolds for $2.5 \mathrm{~kW}$ load are 0.487 , $0.407,0.374$ and $0.3318 \mathrm{~kg} / \mathrm{k}$ Wh. The decrease in bsfc may be due to more oxygen available in the fuel, because of better mixing the helical-spiral manifold having very low bsfc that is $0.3318 \mathrm{~kg} / \mathrm{kW}$.

It is significant to note that $32.03 \%$ of redused in bsfc is observed at $2.5 \mathrm{~kW}$ load for helical-spiral inlet manifold compared to normal inlet manifold.

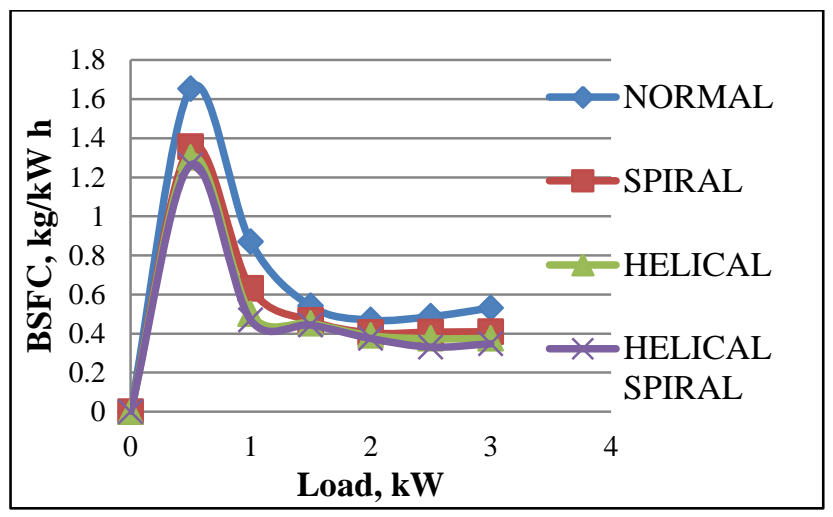

Fig. 4 Load Vs B.S.F.C

It is significant to note that $4.28 \%$ of incresed in brake thermal efficiency observed at $2.5 \mathrm{~kW}$ load for helicalspiral inlet manifold compared to normal inlet manifold.

\subsubsection{Volumetric Efficiency}

It is desirable to maximize the volumetric efficiency of an engine since the amount of fuel that can be burned and power produced for a given engine displacement is maximized. The volumetric efficiency depends on intake manifold configuration, valve size, lift, and timing. Although it does not influence in any way the thermal efficiency of the engine, it will influence the efficiency of the system in which it is installed. Clearly, heavier engines in a vehicle will reduce the fuel economy. Volumetric efficiency variation for new technique inlet manifold and normal inlet manifold with respect to load is shown in the figure.5 It may be observed that, the volumetric efficiency is maximum for Helical manifold and minimum for normal inlet manifold and in between these two spiral and helical-spiral at a given load.

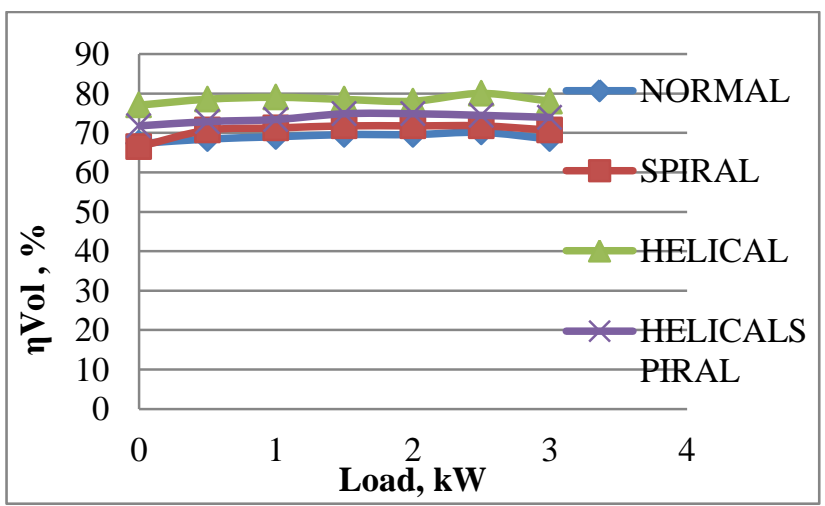

Fig. 5 Load Vs Volumetric Efficiency
Volumetric efficiency of normal manifold is $70.147 \%$ at $2.5 \mathrm{~kW}$ load and for spiral, helical and helical-spiral manifold is $71.79 \%, 80.02 \%$ and $74.46 \%$ respectively. Volumetric efficiency is slightly increased for all new technique inlet manifolds compared to normal manifold.

The helical manifold having the maximum volumetric efficiency compared to all inlet manifolds that is $80.02 \%$. It is significant to note that $9.873 \%$ of incresed in volumetric efficiency observed at $2.5 \mathrm{~kW}$ load for helicalspiral inlet manifold compared to normal inlet manifold

\subsection{Brake Mean Effective Pressure}

Figure.6 depicts the variation of Brake mean effective pressure with respect to at different loads .The brake mean effective pressure is the indication of external shaft work per unit displacement volume done by the engine. Brake mean effective pressures were higher for new intake manifold technique than normal intake manifold.

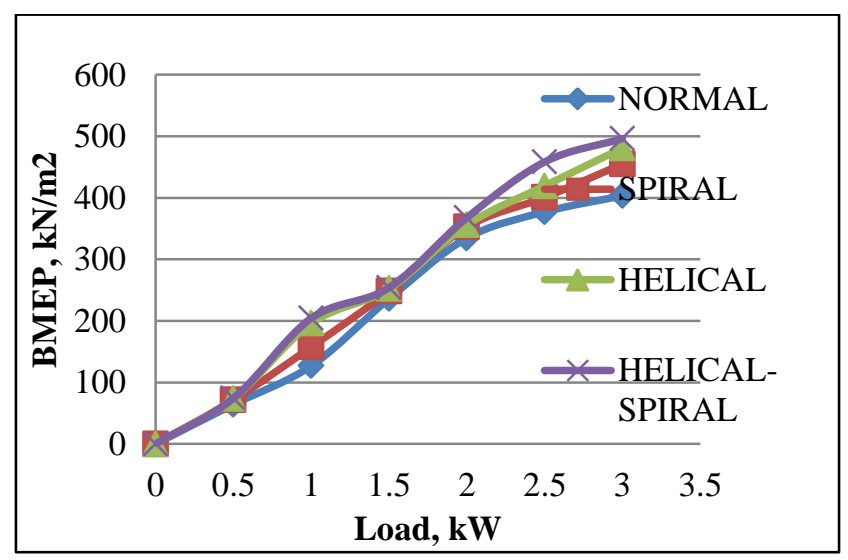

Fig. 6 Load Vs Brake Mean Effective Pressure

The values of brake mean effective pressure at $2.5 \mathrm{~kW}$ of spiral, helical, and helical-spiral inlet manifold are 400.63, $419.30,458.22 \mathrm{kN} / \mathrm{m}^{2}$ where as it is $377.05 \mathrm{kN} / \mathrm{m}^{2}$ for normal manifold. The increase in brake mean effective pressure may increase the power output and decrease the exhaust emissions. It is significant to note that $81.17 \mathrm{kN} / \mathrm{m}^{2}$ of incresed in Brake Mean Effective Pressure observed at $2.5 \mathrm{~kW}$ load for helical-spiral inlet manifold compared to normal inlet manifold.

\subsubsection{Exhaust Gas Temperature}

Figure.7 depicts the variation of exhaust gas temperature for spiral, Helical, helical-spiral and normal manifold for different loads. Exhaust gas temperature is indication for conversion of heat into work that takes place in the cylinder. The exhaust gas temperature is higher for spiral, helical and helical-spiral than normal temperature. At various load conditions it is observed that the exhaust gas temperature increases with load because more fuel is burnt to meet the power requirement. It can be seen that in the case of normal manifold operation exhaust gas temperature is $217{ }^{\circ} \mathrm{C}$ at $2.5 \mathrm{~kW}$ load. 


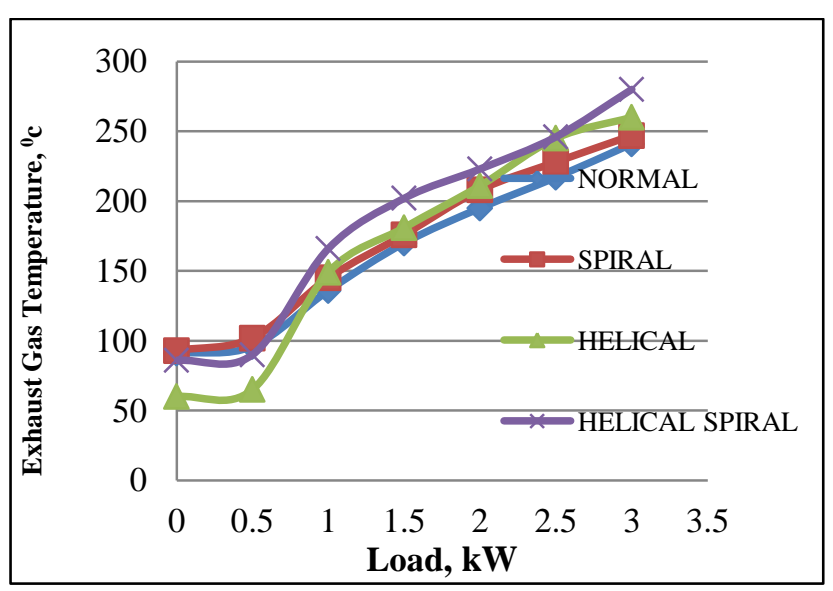

Fig. 7 Load Vs Exhaust Gas Temperature

For spiral, helical and helical-spiral manifold are exhaust gas temperature marginally increases to 228,245 and 246 ${ }^{0} \mathrm{C}$ respectively. The exhaust gas temperature is more for helical-spiral manifold is $281^{\circ} \mathrm{C}$ at $3 \mathrm{~kW}$ load.

\subsection{Engine Emissions}

\subsubsection{HC Emission}

Figure. 8 depicted the variation of hydrocarbons with respect to load for tested different inlet manifold. Unburned hydrocarbon emissions are caused by incomplete combustion of fuel air mixture. HC emissions varies from no load to full load Unburned hydrocarbons are higher in case of spiral manifold compared to normal manifold but in case of helical and helical-spiral manifold will be less. The values of unburned hydrocarbons of spiral, helical and helical-spiral manifolds for constant speed at $2.5 \mathrm{kw}$ load are 46,24 and $22 \mathrm{ppm}$ as compared to $27 \mathrm{ppm}$ of normal manifold. The probable reason for emission may be some portion of the fuel-air mixture in the combustion chamber comes into direct contact with combustion chamber wall and get quenched.

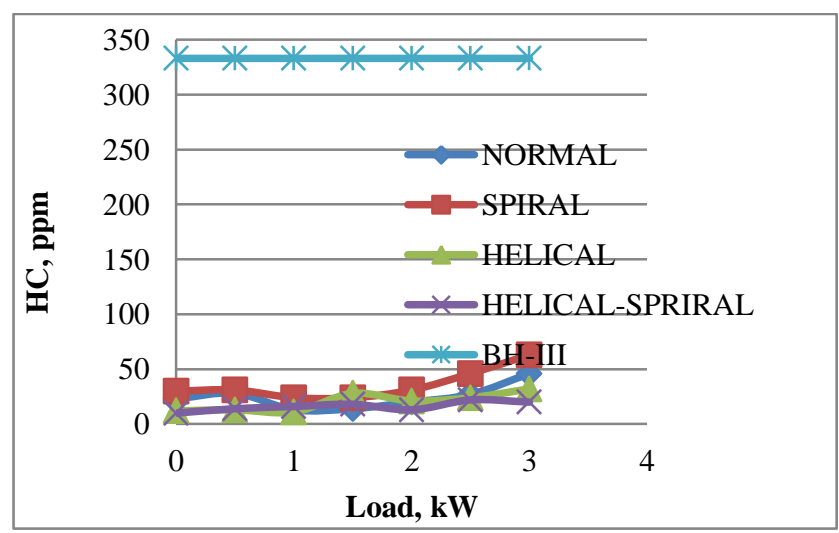

Fig. 8 Load Vs Hydro carbons

Some of this quenched fuel-air mixture is forced out during the exhaust which contributes to the high $\mathrm{HC}$ emission from the results, it can be noticed that the concentration of hydrocarbon of helical-spiral inlet manifold is slightly lower than Normal manifold. Further it can be noted from the graph that emissions of the engine $\mathrm{HC}$ are far below the permissible levels of as per BS-III norms at all the loads.

\subsubsection{CO Emission}

Carbon monoxide occurs only in the engine exhaust .It is resulted as the product of incomplete combustion. From Figure. 9 the variation of carbon monoxide with respect to load can be observed that as the load increases the $\mathrm{CO}$ emission is increased.CO emissions are low at low load and high at full load for normal manifold compared to other manifolds. It can be observed that $\mathrm{CO}$ emissions are decreased in case of helical-spiral manifold up to a load of $2 \mathrm{~kW}$.

The reason behind increased $\mathrm{CO}$ emission may be incomplete combustion. The maximum $\mathrm{CO}$ emission was observed at the full load $3 \mathrm{~kW}$.The values of carbon monoxide of spiral, helical and helical-spiral at load $2.5 \mathrm{~kW}$ are $0.457,0.68,0.742 \%$ by vol respectively where as the value is $0.447 \%$ by vol for normal manifold at $2.5 \mathrm{~kW}$ load. From the graph it can be inferred that at all loads below $3 \mathrm{kw}$ the $\mathrm{CO}$ emission of the engine is in the permissible limits as per BS-III norms and beyond which it is above the permissible norms. Hence engine should be run at loads below $3 \mathrm{~kW}$ load.

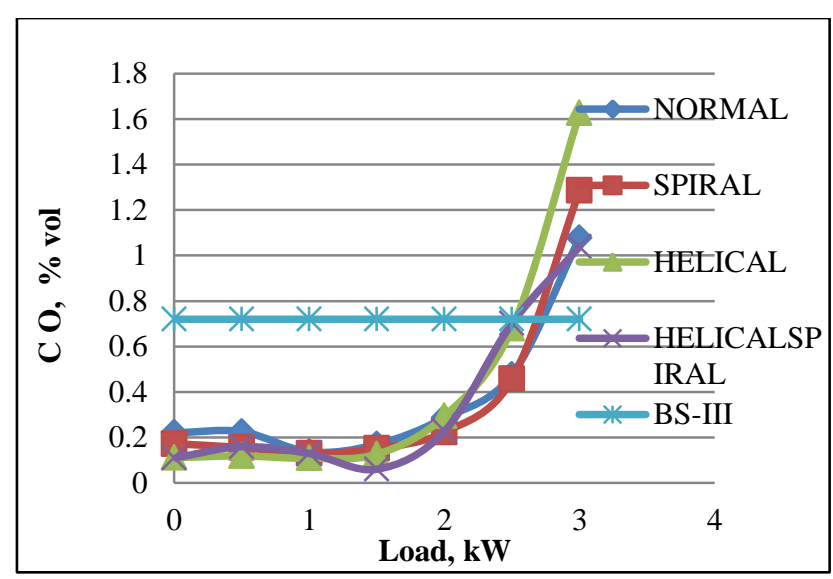

Fig. 9 Load Vs Carbon monoxide

\subsection{3 $\mathrm{NO}_{\mathrm{x}}$ Emission}

Figure.10 Depicts the Oxide of nitrogen from the engine exhaust at different loads. $\mathrm{NO}_{\mathrm{x}}$ results from reaction of nitrogen and oxides at relatively high temperature. No is major component in the $\mathrm{NO}_{\mathrm{x}}$ emission. As the load increases the oxides of nitrogen emission increases . The oxides of nitrogen were higher for spiral and helical manifold at lower loads, as the load increases the emissions were less for all new technique inlet manifold compared to normal manifold. The values of oxides of nitrogen of spiral, helical and helical spiral manifold attachment for constant speed engines at $2.5 \mathrm{~kW}$ load are $392,344,259$ with respected to $430 \mathrm{ppm}$ of normal manifold. 


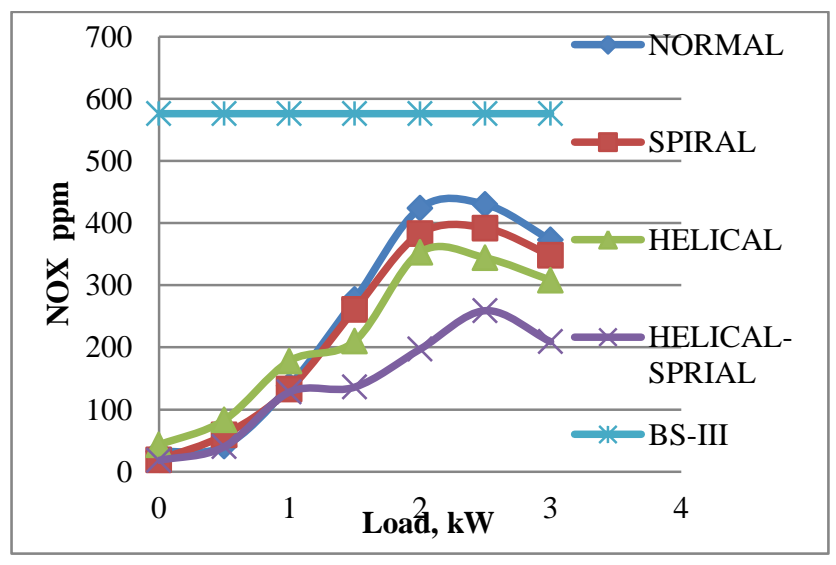

Fig. 10 Load Vs $\mathrm{NO}_{\mathrm{X}}$ Emissions

\section{Conclusions}

It is significant to note that concentration of oxides of nitrogen emissions was redused $171 \mathrm{ppm}$ observed at $2.5 \mathrm{~kW}$ load for helical-spiral inlet manifold compared to normalinlet manifold. Further it can be noted from the graph that emissions of the engine NOx are far below the permissible levels of as per BS-III norms at all the loads.

The following conclusions were drawn on performance and emissions of single cylinder, four stroke, and watered cooled engine while running the engine with three different inlet manifolds

All the three types of inlet manifolds helical, spiral and helical-spiral were found to yields much better performance in comparison with normal manifold.

1.The maximum enhancement in brake thermal efficiency, volumetric efficiency ,Brake specific fuel consumption, Brake mean effective pressure for spiral inlet manifold were found to be $3.4 \%, 1.65 \%, 15.20 \%, 23.58 \mathrm{kN} / \mathrm{m}^{2}$ at $2.5 \mathrm{~kW}$ load.

2.The maximum enhancement in brake thermal efficiency, volumetric efficiency ,Brake specific fuel consumption, Brake mean effective pressure for helical inlet manifold were found to be $5.23 \%, 9.88 \%, 22.08 \%, 42.25 \mathrm{kN} / \mathrm{m}^{2}$ at $2.5 \mathrm{~kW}$ load.

3.The maximum enhancement in brake thermal efficiency, volumetric efficiency ,Brake specific fuel consumption, Brake mean effective pressure for helical-spiral inlet manifold were found to be $8.22 \%, 4.32 \%, 22.08 \%$, $81.17 \mathrm{kN} / \mathrm{m}^{2}$ at $2.5 \mathrm{~kW}$ load.

All the three types of manifolds considered by the present investigation yielded less amount of emissions. To demonstrate the amount of reduction in emissions in comparison with normal inlet manifold are given below table at $2.5 \mathrm{kw}$ load.
Table 1 Experimental comparison emission values

\begin{tabular}{|l|l|l|l|}
\hline Emissions & $\begin{array}{l}\text { Spiral inlet } \\
\text { manifold }\end{array}$ & $\begin{array}{l}\text { Helical inlet } \\
\text { manifold }\end{array}$ & $\begin{array}{l}\text { Helical-Spiral } \\
\text { inlet manifold }\end{array}$ \\
\hline $\mathrm{CO}_{2}$ & $\begin{array}{l}0.22 \% \text { by } \\
\text { vol increased }\end{array}$ & $\begin{array}{l}0.14 \% \text { by vol } \\
\text { increased }\end{array}$ & $\begin{array}{l}0.52 \% \text { by vol } \\
\text { increased }\end{array}$ \\
\hline NOx & $\begin{array}{l}38 \quad \text { ppm } \\
\text { reduced }\end{array}$ & $\begin{array}{l}86 \quad \text { ppm } \\
\text { reduced }\end{array}$ & $\begin{array}{l}171 \text { ppm } \\
\text { reduced }\end{array}$ \\
\hline $\mathrm{HC}$ & $\begin{array}{l}19 \text { ppm } \\
\text { increased }\end{array}$ & $\begin{array}{l}\text { ppm reduced } \\
\text { reduced }\end{array}$ & \\
\hline
\end{tabular}

Engine should be operated below $3 \mathrm{~kW}$ load keeping in view of $\mathrm{CO}$ emission. Beyond which the $\mathrm{CO}$ emission is above the permissible levels of BS-III norms.

4. The exhaust gas temperature increases with the brake power. The exhaust gas temperature is higher for new technique inlet manifold than normal manifold Investigation may be carried out by varying geometrical parameters of inlet manifold and also by various alternativefuels.

Even this present research can be implemented with different engine operating parameters like variable compression ratio (VCR), Exhaust gas recirculation, temperature, and pressure of intake charge and variation of fuel injection timing.

\section{References}

Jorge Martins, 2009, Design of an inlet track of a small IC Engine for swirl enhancement.

Benny Paul, V.Ganesan, 2010, Flow field development in a direct injection diesel engine with different manifolds.

B.Murali Krishna and J.M Mallikarjuna, 2011, Effect of engine speed on in-cylinder tumble flows in a motored internal combustion engine-an Experimental investigation using partial image velocimetry.

F.Payri, J.Bennajes, X.Margot,and A.Gil,2004, CFD modeling of the in-cylinder flow in direct injection diesel engine

K.Kajiyama, k.Nishida An analysis of swirling Flow in cylinder for Predicting D.I .Diesel Engine performanceSAE Paper 840518

Rodney.J,Tabaczynski Effect of inlet and Exhaust System design on Engine performance SAE paper 821577

Teoman Uzkan Characterization of flow produced by a High swirl Inlet Port SAE Paper 830266

S.Alfred Herman,V.Ganesan The effect of induced swirl pattern on TDC flow field in a HSDI Diesel Engine SAE Paper 200526-319

A.Chen, A.Veshagh intake Flow prediction of a Transparent DI Diesel EngineSAE Paper 981020. 